BNL-80227-2008-CP

\title{
Distribution of zinc, resistivity, and photosensitivity in a Vertical Bridgman grown $\mathrm{Cd}_{1-\mathrm{x}} \mathrm{Zn}_{\mathrm{x}} \mathrm{Te}$ ingot
}

V. Babentsov

Institute for Semiconductor Physics, Kiev 03028, Ukraine

J. Franc ${ }^{1}$

Charles University, Faculty of Mathematics and Physics, Institute of Physics, Prague CZ 121 16, Czech Republic

A. Fauler and M. Fiederle

Materialforschungszentrum, Freiburg D-79104, Germany

R. B. James

Nonproliferation and National Security Department, Brookhaven National

Laboratory, Upton, New York 11973

IEEE Nuclear Science Symposium and Medical Imaging Conference

Dresden, Germany/October 19-25, 2008

\section{Nonproliferation and National Security Department Detector Development and Testing Division}

\author{
Brookhaven National Laboratory \\ P.O. Box 5000 \\ Upton, NY 11973-5000 \\ www.bnl.gov
}

Notice: This manuscript has been authored by employees of Brookhaven Science Associates, LLC under Contract No. DE-AC02-98CH10886 with the U.S. Department of Energy. The publisher by accepting the manuscript for publication acknowledges that the United States Government retains a non-exclusive, paid-up, irrevocable, world-wide license to publish or reproduce the published form of this manuscript, or allow others to do so, for United States Government purposes. This preprint is intended for publication in a journal or proceedings. Since changes may be made before publication, it may not be cited or reproduced without the author's permission.

${ }^{1}$ Address all correspondence to this author.

e-mail: franc@karlov.mff.cuni.cz 


\section{DISCLAIMER}

This report was prepared as an account of work sponsored by an agency of the United States Government. Neither the United States Government nor any agency thereof, nor any of their employees, nor any of their contractors, subcontractors, or their employees, makes any warranty, express or implied, or assumes any legal liability or responsibility for the accuracy, completeness, or any third party's use or the results of such use of any information, apparatus, product, or process disclosed, or represents that its use would not infringe privately owned rights. Reference herein to any specific commercial product, process, or service by trade name, trademark, manufacturer, or otherwise, does not necessarily constitute or imply its endorsement, recommendation, or favoring by the United States Government or any agency thereof or its contractors or subcontractors. The views and opinions of authors expressed herein do not necessarily state or reflect those of the United States Government or any agency thereof. 


\title{
Distribution of zinc, resistivity, and photosensitivity in a Vertical Bridgman grown $\mathrm{Cd}_{1-\mathrm{x}} \mathrm{Zn}_{\mathrm{x}}$ Te ingot
}

V. Babentsov

Institute for Semiconductor Physics, Kiev 03028, Ukraine

J. Franc ${ }^{1}$

Charles University, Faculty of Mathematics and Physics, Institute of Physics, Prague CZ 121 16, Czech Republic

A. Fauler and M. Fiederle

Materialforschungszentrum, Freiburg D-79104, Germany

R. B. James

Nonproliferation and National Security Department, Brookhaven National Laboratory, Upton, New York 11973

\begin{abstract}
We present the results of a comprehensive study of distribution of zinc, resistivity, and photosensitivity in a $\mathrm{Cd}_{1-\mathrm{x}} \mathrm{Zn}_{\mathrm{x}} \mathrm{Te}$ ingot grown by the Vertical Bridgman method. We used several complementary methods, viz., glow discharge mass spectroscopy, photoluminescence, resistivity-, and photosensitivity-mapping, along with photo-induced current transient spectroscopy to characterize the material. We identified electronic levels in the band-gap responsible for compensation, recombination, and photosensitivity.
\end{abstract}

\section{Introduction}

Cadmium zinc telluride, $\mathrm{Cd}_{1-\mathrm{x}} \mathrm{Zn}_{\mathrm{x}} \mathrm{Te}(C Z T)$ is a leading material for manufacturing room-temperature $\mathrm{X}$ - and gamma-ray spectroscopic detectors [1-3]. Along with the high atomic numbers $(48,30$, and 52$)$ of its elements, wide band-gap $(1.45 \mathrm{eV}$ at room temperature), and high density $\left(\sim 6 \mathrm{gm} / \mathrm{cm}^{3}\right), \mathrm{CZT}$ offers reasonably good hardness, high resistivity, and good electron transport. Nowadays, the concentration of foreign impurities can be reduced to levels of $10^{14}-10^{15} \mathrm{~cm}^{-3}$, and, to a large extent, native donor and acceptors can assure very accurate compensation conditions [4].

While the High Pressure Bridgman (HPB) process remains as the basic growth method for CZT ingots, we already have grown a 3-inch diameter ingot containing only 3-4 single

\footnotetext{
${ }^{1}$ Address all correspondence to this author.

e-mail: franc@karlov.mff.cuni.cz
} 
crystals using the conventional vertical Bridgman method [5]. Recently, our group correlated increasing resistivity with a corresponding increase in the bandgap throughout CZT ingots [6, 7]. Based on advances in growing crystals and producing detectors, large-volume and pixelmatrix spectroscopic detectors have been devised [8, 9].

There have been several intensive studies of structural extended defects, tellurium inclusions, and $Z n$ inhomogeneities in CZT ingots [10-14]. Less attention has been paid to exploring correlations between $\mathrm{Zn}$ and the native defects that determine the photo-electrical and recombination properties of CZT.

The aim of our research was to compare the distribution of zinc with resistivity $(R)$, photoconductivity (PC), and photoluminescence (PL) throughout the entirety of a vertical Bridgman-grown CZT ingot, and to identify those defects that capture photo-carriers at room temperature.

We measured the content of impurities by Glow Discharge Mass Spectrometry (GDMS). The R and PC maps provided information on the distribution of compensating and photosensitising defects. Low-temperature PL and Photo-Induced Carrier Transient Spectroscopy (PICTS) measurements gave data on the energy levels in the bandgap. We found from assessing the bound exciton (BE) emissions that an increase in the concentration of $\mathrm{Zn}$ affects the deviation from stoichiometry towards the metal excess, thus decreasing the concentration of native defects $\left(\mathrm{V}_{\mathrm{Cd}}, T e_{C d}\right)$ and shallow-level acceptors $\left(N a_{C d}\right)$. We incorporated these data into the overall picture of electronic levels in the bandgap of $C Z T$.

\section{Experimental}

We grew the undoped $\mathrm{Cd}_{1-x} \mathrm{Zn}_{\mathrm{x}} \mathrm{Te}$ ingot by the vertical Bridgman method from a melt containing $5 \% \mathrm{Zn}$. Several wafers were cut along the crystal's axis and two wafers, labelled $\mathrm{S} 1$ and $\mathrm{S} 2$, were cut in a direction perpendicular to them. All the wafers were mechanically lapped, polished, and finally chemo-mechanically polished with a $\mathrm{Br} /$ methanol solution.

We employed a combination of several spectroscopic methods to comprehensively characterize CZT, namely, the contactless $\mathrm{R}$ and PC mapping techniques [15], lowtemperature PL, and PICTS. Photoluminescence spectra were acquired at $4.2-80 \mathrm{~K}$ in a cryostat attached to an $\mathrm{X}-\mathrm{Y}$ translation stage with a 1-mm step, employing an argon laser $(488 \mathrm{~nm})$ for excitation, and a Ge detector. 


\section{Results and discussion}

Table 1 shows the impurity content of the material, primarily $\mathrm{Na}, \mathrm{Cu}$, and $\mathrm{Fe}$, measured in the region of steady-state growth.

Table 1 Glow Discharge Mass Spectroscopy analysis of a CZT ingot (ppbw).

(Vladimir: How about moving up the bottom half of this table, so that it extends across the page rather than leaving a lot of white space? You'd then have four elements in each row. In addition, would you order the elements from the highest to the lowest concentration with those elements below the minimum detection limits placed at the bottom?)

\begin{tabular}{|c|c||c||c||}
\hline $\mathrm{Li}$ & $<1$ & $\mathrm{Fe}$ & 52 \\
\hline $\mathrm{B}$ & 0.4 & $\mathrm{Co}$ & $<0.1$ \\
\hline $\mathrm{Na}$ & 100 & $\mathrm{Ni}$ & 4 \\
\hline $\mathrm{Mg}$ & 14 & $\mathrm{Cu}$ & 25 \\
\hline $\mathrm{Al}$ & 15 & $\mathrm{Zn}$ & Matrix \\
\hline $\mathrm{Si}$ & 13 & $\mathrm{As}$ & 3 \\
\hline $\mathrm{P}$ & 0.3 & $\mathrm{Se}$ & $<10$ \\
\hline $\mathrm{S}$ & 3 & $\mathrm{Ag}$ & $<50$ \\
\hline $\mathrm{Cl}$ & $<1$ & $\mathrm{Cd}$ & Matrix \\
\hline $\mathrm{K}$ & 2 & $\mathrm{In}$ & $<10$ \\
\hline $\mathrm{Ca}$ & 6 & $\mathrm{Sn}$ & $<30$ \\
\hline $\mathrm{Ti}$ & 0.4 & $\mathrm{Sb}$ & $<30$ \\
\hline $\mathrm{V}$ & $<0.1$ & $\mathrm{Te}$ & Matrix \\
\hline $\mathrm{Cr}$ & 2 & $\mathrm{~Pb}$ & $<5$ \\
\hline $\mathrm{Mn}$ & 0.5 & $\mathrm{Bi}$ & $<5$ \\
\hline
\end{tabular}

We inferred the $Z n$ concentration and its distribution in the ingot from the lowtemperature spectral near-bandgap PL measurements that others and we described previously. [7, 8] Fig. 1 maps the distribution of $Z n$ in an axial wafer: an increase in $Z n$ concentration toward the outer part of the ingot is clearly apparent. Vladimir: Any chance you are seeing the effects of strain due to a sticking of the ingot to the crucible and a strain-induced shift in the PL energies? We see the EPDs go up by 100 near the outer part of the ingot. 


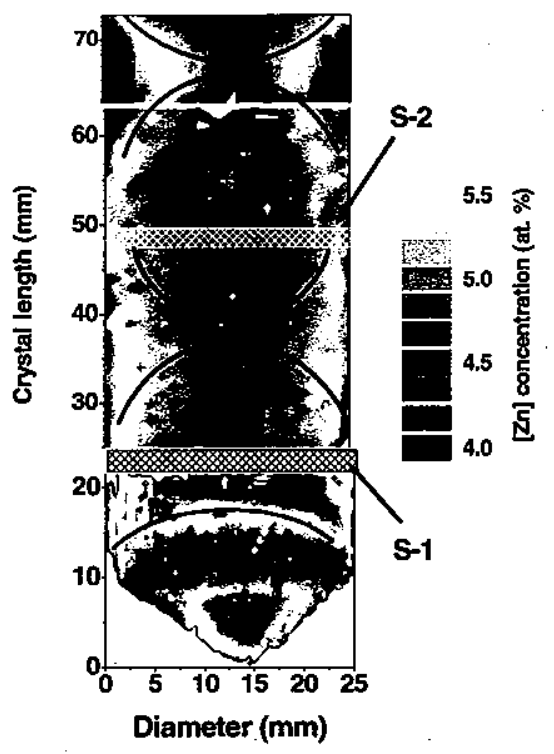

Fig. 1. Map of $\mathrm{Zn}$ concentration in a long-length cut of the CdZnTe ingot.

Fig. 2 is a scan of $\mathrm{Zn}$ distribution along the diameter of the S1 and S2 wafers, cut perpendicularly to the crystal's axis. Generally, the distribution of $\mathrm{Zn}$ in the ingot resembles that reported by V. Komar et al. [13] A remarkable feature is the accumulation of $\mathrm{Zn}$ in the stressed area near the ampoule's wall, also reported by Larson et al. [10]. This finding suggests that the stress induced in the CZT crystal by its contact with the ampoule considerably influences the crystal's homogeneity. [14]
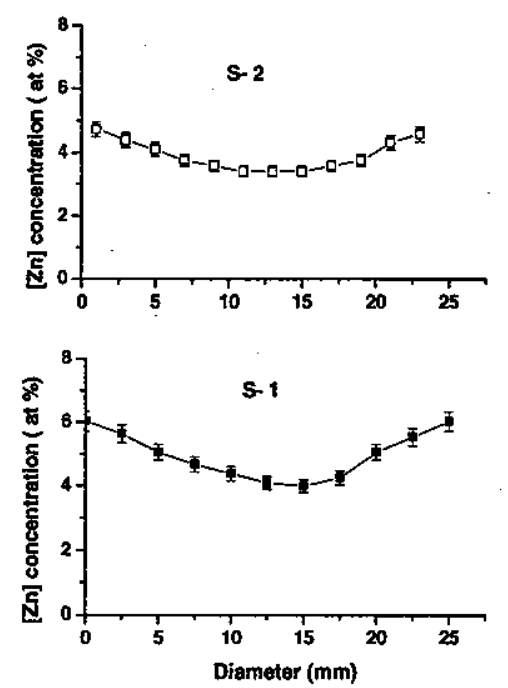
Fig. 2. Radial distribution of zinc in the wafers $S 1$ and $S 2$ cut perpendicular to the crystal's axis.

Fig. 3 shows the resistivity in the dark $(R)$ and photoconductivity $(P C)$ maps in the same wafer. We defined photoconductivity as $\Delta \sigma=\sigma_{\text {light }}-\sigma_{\text {dark }}=1 / R_{\text {light }}-1 / R_{\text {dark }}$. Comparing the distribution of $\mathrm{Zn}$ and resistivity (Fig. 1 and Fig. 3, panel A), we note their strong correlation that we earlier observed. [6, 7] In the regions first-to-freeze and last-to-freeze, this correlation was poor. The outer part of the ingot exhibited the highest resistivity $5 \times 10^{9} \Omega$ $\mathrm{cm}$; thus, in this area compensation was more precise.

A

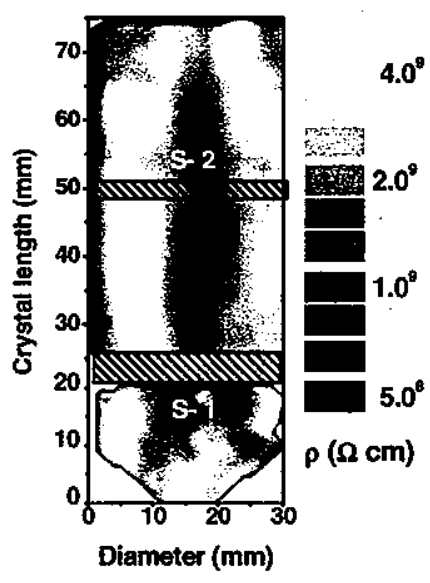

B

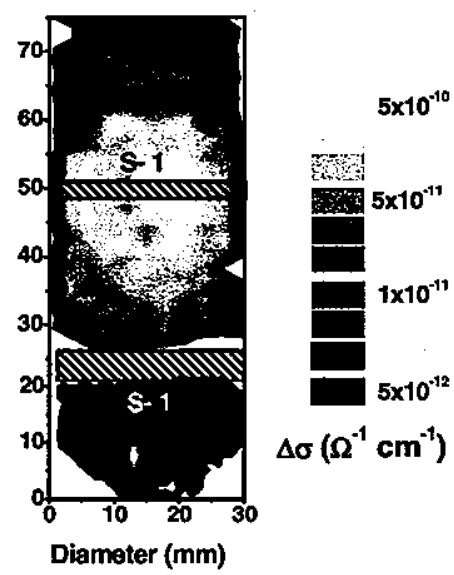

Fig. 3. Resistivity map (A) and photosensitivity map (B) at room temperature in a long-length wafer.

Having obtained these data from the conductivity type and resistivity maps, we should have been able to calculate the location of the Fermi energy over the whole wafer. [16] Unfortunately, in semi-insulated CZT, the type of conductivity and concentration of carriers cannot be evaluated by electrical methods, such as Hall measurements or Thermo-Electric Effect Spectroscopy (TEES).

Nevertheless, using the bound exciton $(B E)$ luminescence, we determined that in our CZT crystal, the concentration of the shallow-donor level dominates that of the shallowacceptor level; knowing this, we tentatively decided that the Fermi-level is located in the upper half of the bandgap. Fig. 4 plots two bound exciton $(B E)$ luminescence spectra taken from the periphery and central part of the ingot. 

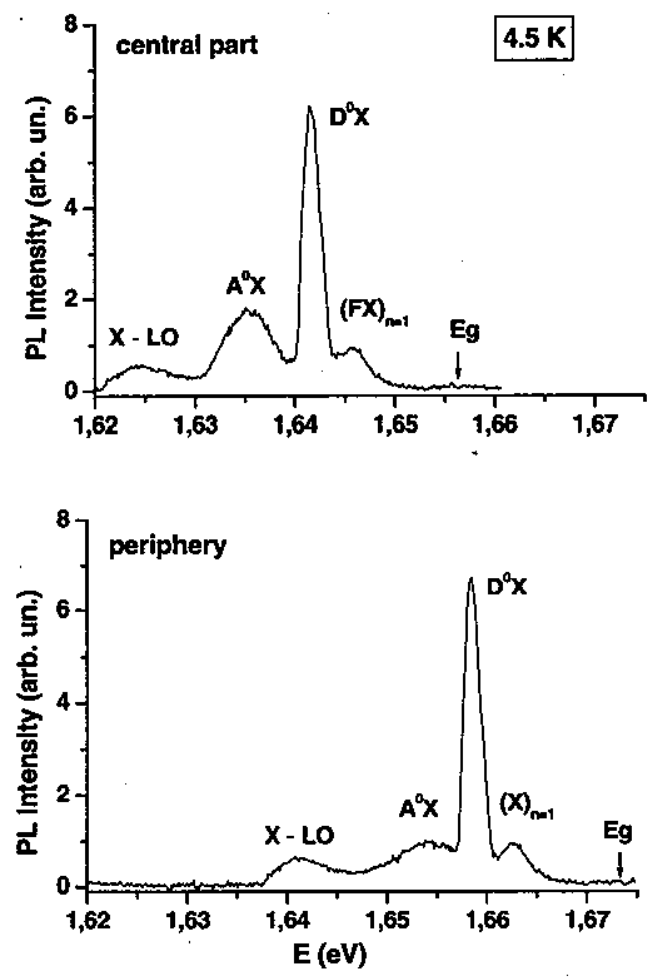

Fig. 4. PL spectra in the bound-exciton region recorded at $4.5 \mathrm{~K}$ in the periphery (bottom) and in the centre (top) of the axial cut.

The $B E$ lines, labelled $\left(A^{0} X\right)$ and $\left(D^{0} X\right)$, arose, respectively, from the recombination of the neutral shallow acceptor $\left(A^{0}\right)$ and the donor $\left(D^{0}\right)$. The relation of $D^{0} X / A^{0} X$ intensities points to the prevalence of the concentration of shallow donors over that of shallow acceptors throughout the cross-section.

The domination of the donor-related component in the $D^{0} X / A^{0} X$ relation is a wellknown characteristic of the n-type $C Z T$; it always appears after annealing the material in cadmium vapor, that is, in cases where the crystalline lattice is enriched with interstitial cadmium. According to the phase diagram of CZT [17], $\mathrm{Cd}$ enrichment lowers the concentrations of $V_{C d}$ and shallow acceptors $\left(M_{C d}\right)$, thus increasing the $D^{0} X / A^{0} X$ ratio. This is a reversible phenomenon, and the $D^{\circ} X / A^{0} X$ ratio again can be depressed by subsequently annealing the n-type $C Z T$ in vacuum. [18-22]

By analogy with these results, the enhancement of the $D^{0} X / A^{0} X$ ratio towards the ingot's periphery suggests a relative increase in the concentration of the shallow donors, namely, a residual amount of sodium impurities in the interstitials, $\mathrm{Na}_{\mathrm{i}}$. [23] According to the GDMS analysis, $\mathrm{Na}$ is the main residual impurity present, at about $100 \mathrm{ppb}$. Thus, we 
conclude that the $\mathrm{Zn}$ concentration is higher, and concentration of $V_{C d}$ and shallow acceptors $N a_{C d}$ lower at the periphery of the ingot than in its central part.

These results are important for analyzing compensation and photosensitivity. Firstly, an increase in $\mathrm{Zn}$ concentration slightly raises the bandgap of $C Z T$, mainly at the expense of the movement of the C-band minimum upwards in the absolute energy scale. Secondly, an increase of resistivity suggests that the Fermi-level in the $n$-type CZT moves towards the midgap, that is, away from the C-band, as is apparent when $N_{D}>N_{A}$ due to the fact that $N_{D}$, $N_{A} \gg N_{D D}, N_{A D}$. Here, $N_{A}$ and $N_{D}$ are the concentration of shallow-level impurities, and $N_{A D}$ and $N_{D D}$ are the concentration of deep-level impurities.

Here we note that even with the values in stoichiometry and the concentration of shallow acceptors remaining constant, that is, solely at the expense of an increase in the concentration of $\mathrm{Zn}$, resistivity must rise in CZT compared with CdTe.

Fig. 3 clearly shows the anti-correlation of resistivity, mapped in the left panel, and photoconductivity, plotted in the right panel. These two maps differ markedly from each other; the highest $R$ values are at the periphery of the wafer, whilst the highest $P C$ values are in its inner part.

Electron $P C$ decreased at the periphery of the ingot, while the Fermi-level moved towards the midgap; this clearly indicates that the $P C$ value fell due to a decline in the deeplevel population of electrons in the dark. Thus, photoelectrons can be easily trapped at deep levels, increasing the afterglow effect. This occurs when a deep-donor level supplies electrons to compensate for a surplus of acceptors.

Thus, from the spatial change in the resistivity and photoconductivity values, we concluded that the deep-donor level in $n$-type CZT is located only several $k T$ away from the Fermi-level, that is at $E_{C}-0.64 \pm 0.1 \mathrm{eV}$. Such a deep level was revealed earlier in CZT by PICTS measurements. Its position was determined in relation to the $V$-band as $E_{V}+(0.75-0.8)$ $\mathrm{eV}$. This deep donor level influences compensation, and was identified as the tellurium antisite, $T e_{C d}$. [24-25].

The maximum value of resistivity in $\mathrm{Cd}_{1-\mathrm{x}} \mathrm{Zn} \mathrm{n}_{\mathrm{x}} \mathrm{Te}$ with $\mathrm{x}=0.05$ can reach approximately of $10^{11} \Omega \times \mathrm{cm}$ when the Fermi level is located slightly above the midgap. A resistivity of $5 \times 10^{9} \Omega$-cm in $n$-type $C Z T$ can be attained when the Fermi-level lies above the midgap.

We obtained additional data for analysing defects from deep-level $P L$. Fig. 5 depicts a typical $P L$ spectrum from the middle of the ingot. 


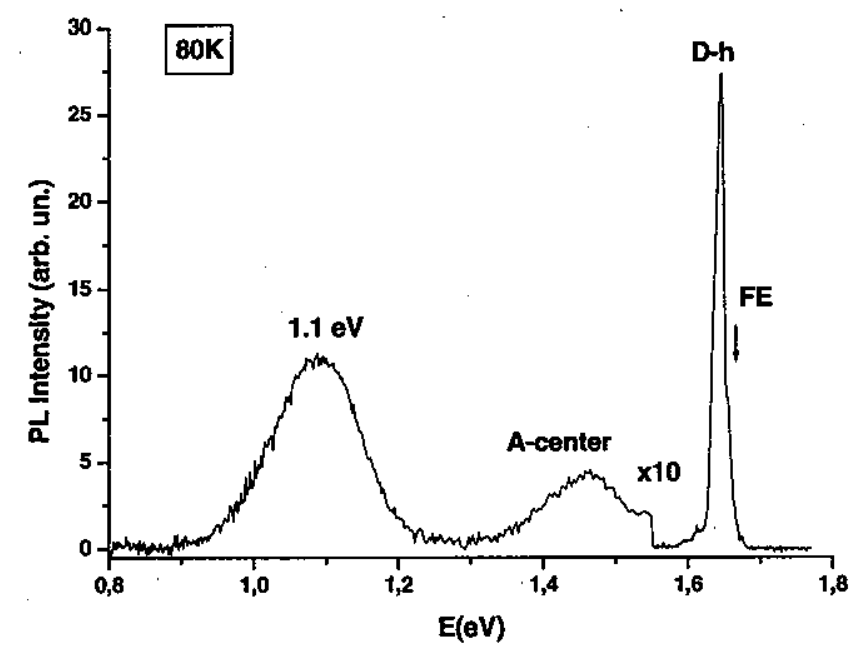

Fig. 5. A typical PL spectrum from the middle of the CZT crystal recorded at $80 \mathrm{~K}$.

The figure shows the PL band, denoted as a free exciton band $(F E)$, that arises from the recombination at shallow donors $(D-h)[26]$, the A-center, and $1.1 \mathrm{eV}$ bands, respectively. The A-band is generated by recombination in the A-center, which is a complex $\left(V_{C d}-M_{C d}\right)$, wherein $M$ is an impurity, such as $I n, G a, A l[27]$ and the $1.1-\mathrm{eV}$ band is due to the Fe and/or $C d$ vacancy complex [4].

Fig. 6 demonstrates that the intensity of the $1.1-\mathrm{eV}$ band correlates with resistivity along the direction of crystal growth. Because the recombination level is located in the lower part of the band-gap, its population does not change, and it does not influence the $P C$ value. 


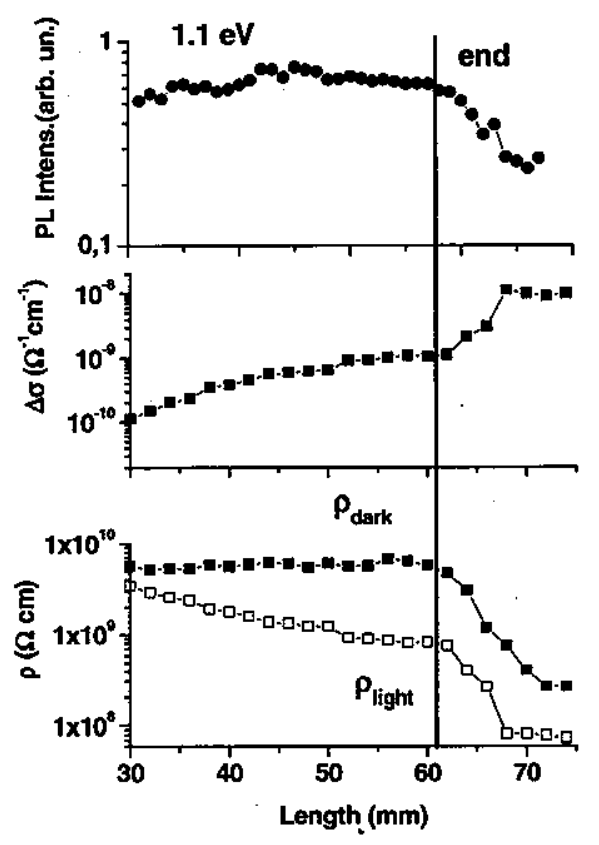

Fig. 6. Axial profiles of resistivity (bottom) in dark $\left(\rho_{\text {dark }}\right)$ and light $\left(\rho_{\text {light }}\right)$, photoconductivity (middle), and intensity of the 1.1-eV PL band (top).

Here again we stress the opposite behavior of $Z n$ concentration and $P C$; as the former decreases, the latter increases. Together with the constant value of $R$ and of the intensity of the 1.1-eV PL band, this finding suggests that the position of the Fermi-level does not change along the crystal, while the population of electrons above the midgap deep-level increases. In other words, a lesser concentration of deep-level electrons was needed to compensate for the rest of acceptors in the area of stable growth. We summarize this situation in Fig. 7, a graphical representation of the bandgap of $\mathrm{Cd}_{1-\mathrm{x}} \mathrm{Zn}_{\mathrm{x}} \mathrm{Te}$ dependence on the $\mathrm{Zn}$ concentration, in which we illustrate the positions of the deep-donor level against the Fermi level (upper panel), and the dependence of the $P C$ signal on the Fermi level (lower panel).

We assume that there is an abundance of defects, such as $V_{C d} T e_{i}$ and $T e_{C d}$, in CZT, as was predicted for CdTe crystals grown from a Te-rich melt [28]. Consequently, the concentrations of these defects should increase to the end of the crystal growth due to prevailing $C d$ evaporation from the melt [29]. While $T e_{C d}$ is a deep donor with an electronic level located above the mid-gap, both $V_{C d}$ and $T e_{i}$ are deep acceptors with electronic levels in the lower part of the gap. $[28,30,31]$ 


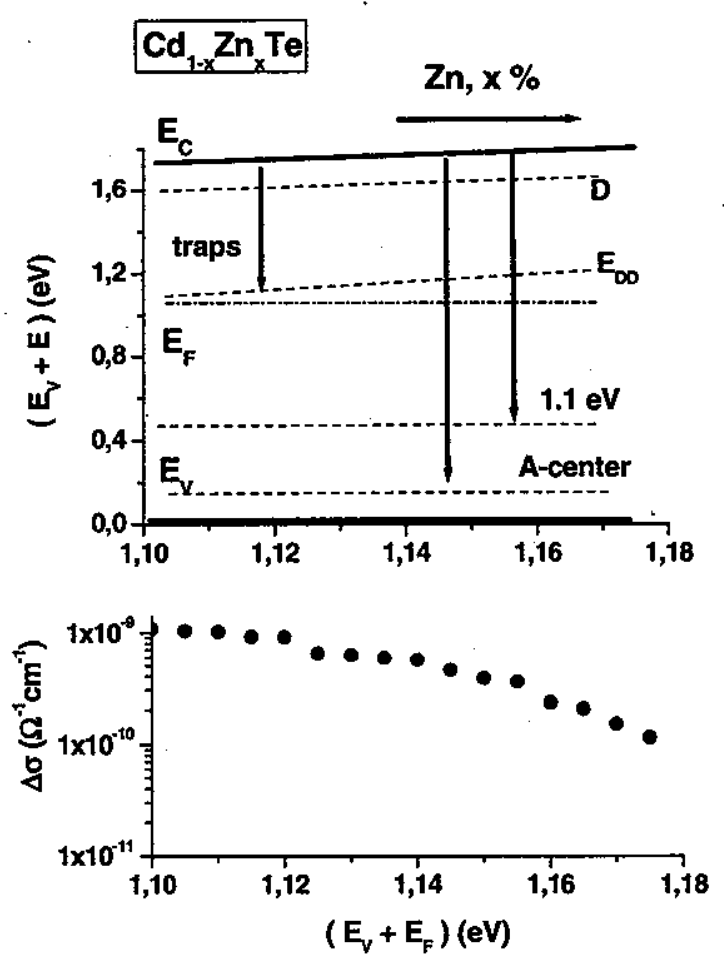

Fig. 7. A representation of the bandgap of $\mathrm{Cd}_{1-\mathrm{x}} \mathrm{Zn} \mathrm{n}_{\mathrm{x}} \mathrm{Te}$ for comparison with the positions of the Fermi level and the energy level of deep-donor level (upper panel), and the dependence of a PC signal on the Fermi level (lower panel).

There are frequent assertions in the literature that the $D^{0} X / A^{0} X$ ratio is more than unity in spectroscopic-grade CZT [2]. The concentration of shallow-level impurities invariably is much greater than that of the deep ones; thus, the $D^{0} X / A^{0} X$ ratio more precisely reflects the deviation from stoichiometry. Materials in which the $D^{0} X / A^{0} X$ ratio is above unity are closer to stoichiometry than the typically grown low resistive $p-C Z T$ in which this relation is always very low. We suppose that a lesser deviation from stoichiometry establishes a nearly equal concentration of shallow donors and shallow acceptors, and, under such conditions, a lower concentration of the deep levels can stabilize the precise compensation condition.

In such condition, deep-level donors and acceptors may compensate each other, and thus, by properly choosing the deep-level compensation conditions, the concentration of electron traps can be minimized to $10^{12} \mathrm{~cm}^{-3}$. Numerical analyses suggest that a compensation condition is reasonably satisfied when $\left(N_{A}+N_{D A}\right)-N_{D} \leq 1 / 2 N_{D D}$. Thus, for a premium-grade CZT, the concentration of $T e_{C d}$, should be about $10^{12} \mathrm{~cm}^{-3}$. This is the reason for the very low yield, and uncontrollable growth of CZT by the High Pressure Bridgman method, wherein 
some impurities, like $C u$ and $F e$, become incorporated into the $C Z T$ crystal from the hot part of growth facilities.

\section{Conclusion}

We undertook a comprehensive study of the distribution of zinc, resistivity, and photosensitivity in a $C Z T$ ingot grown by the Vertical Bridgman method. We demonstrated that resistivity correlates with the distribution of $\mathrm{Zn}$, but photosensitivity does not; the highest photoconductivity was observed in the area with the lowest $Z n$ concentration. We suppose that the distribution of the photosensitising deep-donor, $T e_{C d}$, depends upon a crystal's deviation from stoichiometry. Compared with ingots grown by the High Pressure Bridgman process, the CZT ingot we studied with low $Z n$ concentration exhibited a smaller deviation from stoichiometry, and the Fermi level was located closer to the $C$-band. In our material, the deep-level is more heavily populated with electrons, and thus, it is less efficient as an electron trap.

\section{Acknowledgements}

This work was financially supported by the Grant Agency of the Czech Republic under Grant No. GACR 102/06/0258 and Alexander von Humboldt Foundation. It is also a part of the research plan MSM 0021620834, financed by the Ministry of Education of the Czech Republic. One author (R. B. James) gratefully acknowledges support from the U.S. Department of Energy, Office of Nonproliferation Research and Development, NA-22.

\section{REFERENCES}

1. T. E. Schlesinger, J. E. Toney, H. Yoon, E. Y. Lee, B. A. Brunett, L. Franks: and R. B. James: Cadmium zinc telluride and its use as a nuclear radiation detector material. Mater. Sci. Eng., R 32, 103 (2001).

2. M. Schieber, T. E. Schlesinger, R. B. James, H. Hermon, H. Yoon, and M. Goorsky, Study of impurity segregation, crystallinity, and detector performance of melt-grown cadmium zinc telluride crystals, J. Cryst. Growth, 237-239, 2082 (2002).

3. M. Fiederle, V. Babentsov, J. Franc, A. Fauler, and J.-P. Konrath, Growth of high resistivity CdTe and (Cd,Zn)Te crystals, Cryst. Res. Technol. 38, 588-597, (2003). 
4. M. Fiederle, V. Babentsov, A. Fauler, W. Witte, K.W. Benz and R. B. James, Semiinsulating cadmium telluride at low impurity concentrations, J. Mater. Res. 19, 405408 (2004).

5. M. Fiederle, A. Fauler, V. Babentsov, J. Franc, J. Konrath, M. Webel, J. Ludwig, and K. W. Benz, Characterization of CdTe crystals grown by the vertical Bridgman method, Nucl. Instrum. Meth. Phys. Res. A. 509, 70-75 (2003).

6. M. Fiederle, A. Fauler, V. Babentsov, J. Franc, and K.-W. Benz, Resistivity dependence on $\mathrm{Zn}$ concentration in semi-insulating $(\mathrm{Cd}, \mathrm{Zn}) \mathrm{Te}$, Proceedings of the SPIE, X-Ray and Gamma-Ray Detectors and Applications IV. Editor(s): James, Ralph B.; Franks, Larry A.; Burger, Arnold; Westbrook, Edwin M.; Durst, Roger D. Proc. SPIE, 4784, 14-20 (2002).

7. V. Corregidor, V. Babentsov, E. Diéguez, J. L. Castaño, M. Fiederle, A. Fauler, and K. W. Benz, Correlation of resistivity with zinc content in vapor grown (Cd,Zn)Te:Se, Appl. Phys. Lett. 81, 5153-5 (2002).

8. M. Amman, J. S. Lee, and P. N. Luke, Electron trapping nonuniformity in highpressure-Bridgman-gown CdZnTe, J. Appl. Phys., 92 (6), 3198-3206 (2002).

9. J. Ludwig, A. Zwerger, K.W. Benz, M. Fiederle, H. Braml, A. Fauler, and J. P. Konrath, X-ray energy selected imaging with Medipix II, Nucl. Instr. Meth. A 531, 12 (2004)

10. D. J. Larson Jr., R. P. Silberstein, D. Di Marzo, F. C. Carlson, D. Gillies, G. Long, M. Dudley, and J. Wu, Compositional, strain contour and property mapping of CdZnTe boules and wafers, Semicond. Sci. Technol. 8, (6S) 911-15 (1993).

11. J. R. Heffelfinger, D. L. Medlin, and R. B. James, Analysis of Grain Boundaries, Twin Boundaries and Te Inclusions in Cadmium Zinc Telluride Grown by High-pressure Bridgman Method, in Semiconductors for Room Temperature Radiation Detector Applications II, Vol. 487, edited by R. B. James, T. E. Schlesinger, P. Siffert, W. Dusi, M. R. Squillante, M. O'Connell and M. Cuzin (Materials Research Society, Pittsburgh, PA, 1998), p. 33.

12. T. E. Schlesinger, M. Greaves, S. Ross, B. A. Brunett, J. M. Van Scyoc, and R. B. James, Role of uniformity and geometry in Imarad-type gamma-ray spectrometers, SPIE Proceedings Series, Vol. 3768, pp 16, (1999).

13. V. Komar, A. Gektin, D. Nalivaiko, I. Klimenko, V. Migal, O. Panchuk, and A. Rybka, Characterization of CdZnTe crystals grown by HPB method, Nucl. Instr. and Meth. A, Vol. 458, 113-122 (2001). 
14. H. Zhang, D. J. Larson Jr., C. L. Wang, and T. H. Chen, Growth without wall contact, J. Cryst. Growth, 250, 215-222 (2003).

15. R. Stibal, J. Windscheif, and W. Jantz, Contactless evaluation of semiinsulating GaAs wafer resistivity using time-dependent charge measurements, Semicond. Sci. Technol., 6, 995 (1991).

16. V. Babentsov, J. Franc, H. Elhadidy, A. Fauler, M. Fiederle, and R.B. James, Dependence of the $\mathrm{Sn}^{0 / 2+}$ charge state on the Fermi level in semi-insulating CdTe, J. Mater. Res., 22, 3249-3254 (2007).

17. J. H. Greenberg, P-T-X phase equilibrium and vapor pressure scanning of nonstoichiometry in the CdeZneTe system, Progress in Crystal Growth and Characterization of Materials, 47 196-238 (2003).

18. J. M. Francou, K. Saminadayar, and J. L. Pautrat, Shallow donors in CdTe, Phys. Rev. B41, (17) 12035-41 (1990).

19. S. Seto, A. Tanaka, Y. Masa, S. Dairaku, and M. Kawashima, Annealing behavior of bound exciton lines in high quality CdTe, Appl. Phys. Lett. 53, 1524 (1988).

20. V. N. Babentsov, Z. K. Vlasenko, A. I. Vlasenko, and A. V. Lyubchenko, Distribution of a shallow donor impurity in a p-type CdTe wafer annealed in $\mathrm{Cd}$ vapors, Semiconductors. 31, 441-443 (1997).

21. S. H. Song, J. F. Wang, G. M. Lalev, L. He, and M. Isshiki, Photoluminescence characterization of Cd-annealing effects on high-purity CdTe single crystals, J. Cryst. Growth 252 (1), 102-106 (2003).

22. E. Belas, J. Franc, R. Grill, A. L. Toth, P. Horodysky, P. Moravec and P. Höschl, Regular and anomalous-type conversion of p-CdTe during Cd-rich annealing, Journal of Electronic Materials, 34, 957-962 (2005).

23. U. Becker, H. Zimmermann, P. Rudolph, and R. Boyn: Optical Study of the Impurity Distribution in Vertical-Bridgman-Grown CdTe Crystals. Physica Status Solidi (a) 112, 569 (1998).

24. M. Fiederle, C. Eiche, M. Salk, R. Schwarz, and K. W. Benz, Modified compensation model of CdTe. Journal of Applied Physics, 84 (12) 6689-92 (1998).

25. M. Chu, S. Terterian, D. Ting, C. C. Wang, H. K. Gurgenian, and Sh. Mesropian, Tellurium antisites in CdZnTe, Appl. Phys. Lett. 79, 2728 (2001).

26. Zhonghai Yu, S.G. Hofer, N. C. Giles, T. H. Myers, and C. J. Summers, Interpretation of near-band-edge photoreflectance spectra from CdTe, Phys. Rev. B 51, (19) 13789$92(1995)$. 
27. W. Stadler, D. M. Hofmann, H. C. Alt, T. Muschik, B. K. Meyer, E. Weigel, G. Müller-Vogt, M. Salk, E. Rupp, and K. W. Benz, Optical Investigations of Defects in $\mathrm{Cd}_{1-\mathrm{x}} \mathrm{Zn}_{\mathrm{x}} \mathrm{Te}$, Phys. Rev. B 51, (16) 10619-10630 (1995).

28. M. Berding, Native defects in CdTe, Phys. Rev. B 60 (12) $8943-50$ (1999).

29. P. Rudolph, Non-stoichiometry related defects at the melt growth of semiconductor compound crystals-a review, Crystal Research and Technology, 38, 542-554 (2003).

30. Cs. Szeles, Y. Y. Shan, K. G. Lynn, and A. R. Moodenbaugh, Trapping Properties of Cadmium Vacancies in $\mathrm{Cd}_{\mathrm{l}-\mathrm{x}} \mathrm{Zn}_{\mathrm{x}}$ Te, Phys. Rev. B. 55(11) 6954-6949 (1996). 